Revista Brasil. Bot., V.31, n.3, p.507-516, jul.-set. 2008

\title{
Morfologia de frutos, sementes, plântulas e mudas de Senna multijuga var. lindleyana (Gardner) H. S. Irwin \& Barneby - Leguminosae Caesalpinioideae $^{1}$
}

\author{
ISAAC LUCENA DE AMORIM ${ }^{2}$, ANTONIO CLAUDIO DAVIDE ${ }^{3}$, \\ ROBÉRIO ANASTÁCIO FERREIRA ${ }^{4,6}$ e MARIA MADALENA FERREIRA CHAVES ${ }^{5}$
}

(recebido: 07 de outubro de 2004; aceito: 03 de julho de 2008)

\begin{abstract}
Morphology of fruits, seeds and seedlings of Senna multijuga var. lindleyana (Gardner) H. S. Irwin \& Barneby - Leguminosae Caesalpinioideae). We described and illustrated the external and internal morphology of fruits and seeds and the external morphology of seedlings of Senna multijuga. The work was carried out in laboratory and forest nursery conditions. We detected useful characters to identify this species both in laboratory (in seed analyses) and field studies (ecology and regeneration). The main fruit characters described were: dehiscence, shape, color and pericarp texture. The main seed characters described were: closed pleurogram, shape and persistence of cotyledons, areole and endosperm; of the seedlings: aspects of young stem, shape and persistence of cotyledons, leaf arrangement, presence of hair and glands and shape of eophyll.
\end{abstract}

Key words - fruit, morphology, seed, seedlings, Senna multijuga

RESUMO - (Morfologia de frutos, sementes, plântulas e mudas de Senna multijuga var. lindleyana (Gardner) H. S. Irwin \& Barneby - Leguminosae Caesalpinioideae). Os objetivos deste trabalho foram descrever e ilustrar os aspectos morfológicos externos e internos de frutos e sementes e os aspectos externos de plântulas e mudas de Senna multijuga. O trabalho foi realizado em laboratório e viveiro florestal. A espécie apresentou características importantes que podem auxiliar na sua identificação, tanto em laboratórios para análise da qualidade fisiológica e em viveiros de produção de mudas, quanto em estudos da ecologia da espécie, sob o aspecto da regeneração natural. Características dos frutos, principalmente a deiscência, forma, coloração e textura do pericarpo, comuns na subfamília; de sementes como presença de pleurograma fechado, aréola e endosperma; de plântulas e mudas como aspectos da superfície do caulículo, forma e persistência dos cotilédones, filotaxia, presença de pêlos e glândulas e forma dos protófilos constituíram-se nos principais elementos para identificação da espécie.

Palavras-chave - fruto, morfologia, plântulas, semente, Senna multijuga

\section{Introdução}

Para os taxonomistas, as diferenças entre plantas, assim como as características em comum, são susceptíveis de avaliação em larga escala pelos caracteres morfológicos $\mathrm{e}$, tais caracteres manifestam-se por componentes estruturais. Deste modo, o valor dos caracteres morfológicos é apreciado pela constância. Portanto, quanto maior for

1. Parte da Dissertação de Mestrado do primeiro autor, Programa de Pós-Graduação em Engenharia Florestal, Universidade Federal de Lavras, Lavras.

2. Universidade Federal de Campina Grande, Departamento de Ciências Básicas - Caixa Postal 64, 58700-900 Patos, PB, Brasil.

3. Universidade Federal de Lavras, Departamento de Ciências Florestais, Caixa Postal 3037, 37200-000 Lavras, MG, Brasil.

4. Universidade Federal de Sergipe, Departamento de Engenharia Agronômica, Av. Marechal Rondon, S/N, Jardim Rosa Elze, 49100-000 São Cristóvão, SE, Brasil.

5. Universidade Federal de Lavras, Departamento de Ciências Florestais, Caixa Postal 3037, 37200-000 Lavras, MG, Brasil.

6._Autor para correspondência: raf@ufs.br a sua constância, maior a confiança que neles se pode depositar (Lawrence 1973). Deve-se considerar que, para tal objetivo, a constância somente pode ser válida quando está presente num grande número de indivíduos da família, gênero ou espécie.

Para muitos autores, a grande dificuldade de se estudar a estrutura, a fenologia e o comportamento de uma espécie, dentro de uma comunidade vegetal, é a sua identificação. Neste sentido, Roderjan (1983) e Pinheiro (1986), mencionam três caminhos: a taxonomia botânica, que utiliza os órgãos reprodutivos das plantas; a anatomia da madeira, que faz uso dos elementos constitutivos do lenho e a dendrologia, que se baseia nas características macroscópicas dos órgãos vegetativos. Além destes, conforme enfatiza Oliveira (1993), a morfologia de plantas também tem merecido atenção, quer seja como parte de estudos morfo-anatômicos para ampliar o conhecimento sobre determinada espécie ou agrupamento sistemático de plantas, ou para facilitar a identificação de plantas de uma região, dentro de um enfoque ecológico. 
Na tentativa de ampliar as informações sobre aspectos morfológicos de espécies arbóreas, de modo a propiciar informações básicas para a identificação destas em laboratórios de sementes, viveiros florestais e em estudos sobre os aspectos de regeneração natural em vários ecossistemas, observa-se que mais recentemente há esforços para tornar isto mais habitual. Assim, algumas espécies descritas e ilustradas a exemplo de Acacia polyphylla DC. (Araujo-Neto et al. 2002), Amburana cearensis (Allemão) A.C. Smith (Cunha \& Ferreira 2003), Sesbania virgata (Cav.) Pers. (Araujo et al. 2004), Byrsonima intermedia A. Juss. (Souto \& Oliveira 2005) e Pilocarpus pennatifolius Lem. (Souza et al. 2005), Drimys brasiliensis Miers (Abreu et al. 2005), Balfourodendron riedelianum (Engler) Engler (Silva \& Paoli 2006), Himatanthus drasticus (Mart.) Plumel. (Amaro et al. 2006), Dinizia excelsa Ducke e Cedrelinga catenaeformis Ducke (Melo \& Varela 2006), Trema micrantha (L.) Blume (Amorim et al. 2006) podem ser utilizadas para tal finalidade. Os autores apresentam caracteres descritos e ilustrados de frutos, sementes, plântulas e mudas (fase jovem), que podem ser seguramente utilizados para identificação das espécies.

A identificação de plantas, no estádio juvenil, é tarefa árdua que dificilmente é completada, isto porque os caracteres morfológicos externos de uma planta, nos estádios iniciais de desenvolvimento, podem ser diferentes daqueles observados no indivíduo adulto. Do mesmo modo, plântulas de espécies e gêneros afins, que normalmente apresentam semelhanças morfológicas externas, tornam a identificação das espécies imprecisa e às vezes até impossível (Pinheiro 1986). Portanto, nos estudos que envolvem a necessidade de conhecimento da regeneração natural, a identificação da planta no estádio juvenil torna-se imprescindível. Segundo Salles (1987), a identificação das plantas neste estádio contribui para um melhor entendimento da biologia das espécies, amplia os estudos taxonômicos e facilita o reconhecimento das espécies em estudos de regeneração por sementes, em condições naturais.

Com relação aos estudos morfológicos de frutos, sementes, plântulas e mudas, observa-se que apesar de serem variados e dispersos, fornecem valiosas informações que permitem a identificação de muitas espécies em fases juvenis. Tal conhecimento é imprescindível quando se pretende compreender o ciclo biológico e a regeneração natural das espécies (Oliveira 1993). Do mesmo modo, estes estudos podem ser empregados para outros fins como: análise em laboratório, identificação e diferenciação de espécies em viveiros e reconhecimento da planta no campo, havendo, portanto, a necessidade de estímulos a esses estudos básicos.
Vários autores têm contribuído para ampliar os estudos morfológicos com espécies de Leguminosae Caesalpinioideae. Dentre eles pode-se citar: Finger et al. (1979), Gunn (1981), Oliveira \& Pereira (1984), Flores \& Benavides (1990), Araújo \& Matos (1991), Soriano \& Torres (1992), Silva \& Matos (1998), Oliveira (1999), Botelho et al. (2000) e Ferreira et al. (2001).

Senna multijuga (Rich.) H.S. Irwin \& Barneby, conhecida por pau-cigarra, caqueira, aleluia, canafístula (Lorenzi 1992), angico-branco, acácia, amarelinho(a), chuva-de-ouro, pau-fava, piúna (Carvalho 1994) e cássiaverrugosa, é uma Leguminosae Caesalpinioideae, comum nas regiões Sudeste, Sul e Nordeste do Brasil (Lorenzi 1992 e Davide et al. 1995) e no Distrito Federal (Carvalho 1994). É uma espécie ornamental, amplamente empregada na arborização urbana e a sua madeira pode ser usada na caixotaria, confecção de brinquedos e para lenha e carvão (Lorenzi 1992). Ecologicamente exerce importante papel, pois apresenta potencial para utilização em recuperação de áreas mineradas (Carvalho 1994).

Deste modo, este trabalho teve como objetivos: a) descrever e ilustrar os caracteres morfológicos externos e internos dos frutos e sementes de Senna multijuga var. lindleyana e b) fornecer descrições da morfologia externa das plântulas e mudas, ilustrando-se os principais caracteres para sua identificação.

\section{Material e métodos}

O presente trabalho foi desenvolvido no Laboratório de Sementes Florestais (LSF) e Viveiro Florestal, do Departamento de Ciências Florestais (DCF), da Universidade Federal de Lavras (UFLA). A espécie foi escolhida em função da sua grande ocorrência na região, da sua importância ecológica e da ausência de estudos neste sentido, uma vez que é bastante promissora para utilização em programas de recuperação de áreas degradadas e recomposição de matas ciliares.

Colheita e beneficiamento de sementes - Foram colhidos, manualmente e com auxílio de podão, frutos de cinco matrizes selecionadas em populações naturais, em remanescentes florestais na região de Lavras - MG, distantes no mínimo $100 \mathrm{~m}$ entre si. Estes foram colocados em sacos plásticos, previamente etiquetados e conduzidos ao LSF para o beneficiamento. As amostras foram misturadas, retirando-se uma sub-amostra aleatória de 100 frutos para descrição morfológica. O restante foi beneficiado manualmente, conforme sugestão de Davide et al. (1995). As sementes sadias, limpas e livres de injúrias mecânicas, foram colocadas para secar à sombra, sendo em seguida, acondicionadas em sacos plásticos transparentes e impermeáveis e armazenadas em câmara fria do LSF, em temperatura de $10^{\circ} \mathrm{C}$ e umidade relativa do ar de $60 \%$. 
Morfologia dos frutos e sementes - Foram utilizados frutos sadios, inteiros e sem deformações, nos quais se observou os detalhes externos e internos do pericarpo, número de sementes por fruto, deiscência e caracteres eventuais. As sementes utilizadas estavam isentas de atrofiamentos, injúrias, ataque de insetos e livres de impurezas. Foram feitos cortes transversais e longitudinais com lâminas de aço para observação da consistência e do tamanho do endosperma em relação ao embrião, bem como a sua posição no interior da semente. No estudo da estrutura interna, as sementes foram submetidas à fervura por três minutos para o amolecimento e reidratação. Os parâmetros morfológicos analisados foram: a) externos - dimensões (comprimento, largura e espessura), envoltórios (tegumentos - testa e tégmen), coloração, textura, consistência, forma, posição do hilo e da micrópila e outros caracteres eventuais; b) internos - presença ou ausência de endosperma e, no embrião (cotilédone, eixo hipocótiloradícula e plúmula) analisou-se o tipo, a forma, coloração, posição em relação à semente e dimensões, com auxílio de um microscópio estereoscópico binocular. Utilizando-se uma régua milimetrada e paquímetro do tipo Weysberf, com precisão de $0,05 \mathrm{~mm}$, foram realizadas as medidas de comprimento, largura e espessura de uma amostra tomada aleatoriamente de 100 frutos e 100 sementes, obtendo-se os valores mínimo, médio e máximo.

A metodologia e a terminologia empregada, assim como os parâmetros observados para as descrições, basearam-se nos trabalhos de Ferri et al. (1981), Irwin \& Barneby (1982), Kuniyoshi (1983), Vidal \& Vidal (1984), Oliveira \& Pereira (1984), Lima (1985) Rodrigues \& Araki (1988), Feliciano (1989), Lima (1989/1990), Beltrati (1992), Chaves (1994) e Barroso et al. (1999).

Morfologia das plântulas e mudas - Para o acompanhamento do crescimento das plântulas e mudas, foram produzidos 50 indivíduos em casa de vegetação, por meio de semeadura direta em sacos de polietileno preto $(10 \times 20 \times 0,1 \mathrm{~cm})$, tendo como substrato terra de subsolo e casca de arroz carbonizada, na proporção 8:3. Para cada $60 \mathrm{~L}$ de substrato foi adicionado $1 \mathrm{~kg}$ de superfosfato simples. As plântulas e mudas tiveram seu crescimento acompanhado, anotando-se e ilustrando-se todos os detalhes morfológicos externos.

Foram consideradas três fases para descrição e acompanhamento do desenvolvimento das plântulas e mudas, baseadas na metodologia utilizada por Feliciano (1989): a) Primeira fase - desde o intumescimento das sementes até a emissão dos cotilédones, porém sem os protófilos formados; b) Segunda fase - iniciada quando o primeiro protófilo estava completamente formado; e c) Terceira fase - a partir do surgimento do pronomófilo, ou ainda, quando a planta adquiriu diâmetro do colo de $3 \mathrm{~mm}$ ou altura de $30 \mathrm{~cm}$. Cada fase foi acompanhada detalhadamente, verificando-se todos os caracteres morfológicos, além de características de crescimento, possivelmente diferenciativas e úteis na identificação.

Para a análise descritiva foram tomados os indivíduos sadios, e destes, apenas um, foi utilizado para ilustração.
Os elementos vegetativos observados foram: raiz, colo, hipocótilo, epicótilo, caule jovem, cotilédones, protófilos, metáfilos, gemas, estípulas, brácteas, catáfilos, pêlos e glândulas. A metodologia e a terminologia empregada, assim como os parâmetros observados para as descrições seguiram com base nos trabalhos de Radford et al. (1974), Ferri et al. (1981), Roderjan (1983), Vidal \& Vidal (1984), Feliciano (1989), Oliveira (1993) e Chaves (1994).

Herborização e ilustração - O material testemunho deste estudo, coletado na cidade de Lavras, Minas Gerais por Amorim, encontra-se sob registro 13246, depositado no Herbário do Departamento de Biologia da UFLA (ESA). Todo o material das fases de plântula e muda foi conservado em FAA (Formaldeído 35\%, ácido acético glacial concentrado e álcool etílico $70 \%$, na proporção de 1:1:18), conforme prescrito por Ferreira et al. (1995). A herborização das plântulas e mudas foi feita a partir da secagem do material em estufa a $60{ }^{\circ} \mathrm{C}$ por 24 horas, em seguida colocado em cartolina e recoberto com plástico transparente. As ilustrações foram feitas manualmente, de material sadio bem desenvolvido e representativo de cada fase, com auxílio de um microscópio estereoscópico binocular.

\section{Resultados e discussão}

Morfologia dos frutos (figura 1A-C) - O fruto é um legume seco, deiscente, polispérmico e monocarpelar, com comprimento médio de 154,0 mm (variando de 121,0 a $188,0 \mathrm{~mm}$, com desvio padrão de $19,7 \mathrm{~mm}$ e coeficiente de variação de 12,8\%); largura média de 15,4 mm (variando de 12,0 a 18,0 mm, com desvio padrão de $1,6 \mathrm{~mm}$ e coeficiente de variação de $10,42 \%$ ) e espessura média de $1,0 \mathrm{~mm}$ (variando de 0,8 a $1,3 \mathrm{~mm}$, com desvio padrão de $0,1 \mathrm{~mm}$ e coeficiente de variação de $10 \%$ ). Apresenta ápice truncado, tendo um curto gancho no centro, tornado-se acuminado e a base é cuneada a curto acuneada ou oblíqua; com bordos inteiros, retos ou levemente curvos, paralelos e impressos, contornados pelas linhas de sutura ventral e dorsal. A superfície é brilhante, glabra e marrom-escura nos bordos, com ondulações transversais de tonalidade café sobre os núcleos seminíferos. O pericarpo é seco, delgado, subcoriáceo e quebradiço, apresentando superfície interna palha-escura, brilhante e glabra, constituída de inúmeros lóculos (em média 30), que são oblongos e transversais ao comprimento do fruto.

Dentre as Leguminosae Caesalpinioideae, Barroso et al. (1999) classificam 11 tipos de frutos, dentre eles o legume como observado em Senna multijuga, que segundo os autores, quando associadas às características das sementes e dos embriões fornecem informações de grande importância para identificação dos táxons. 


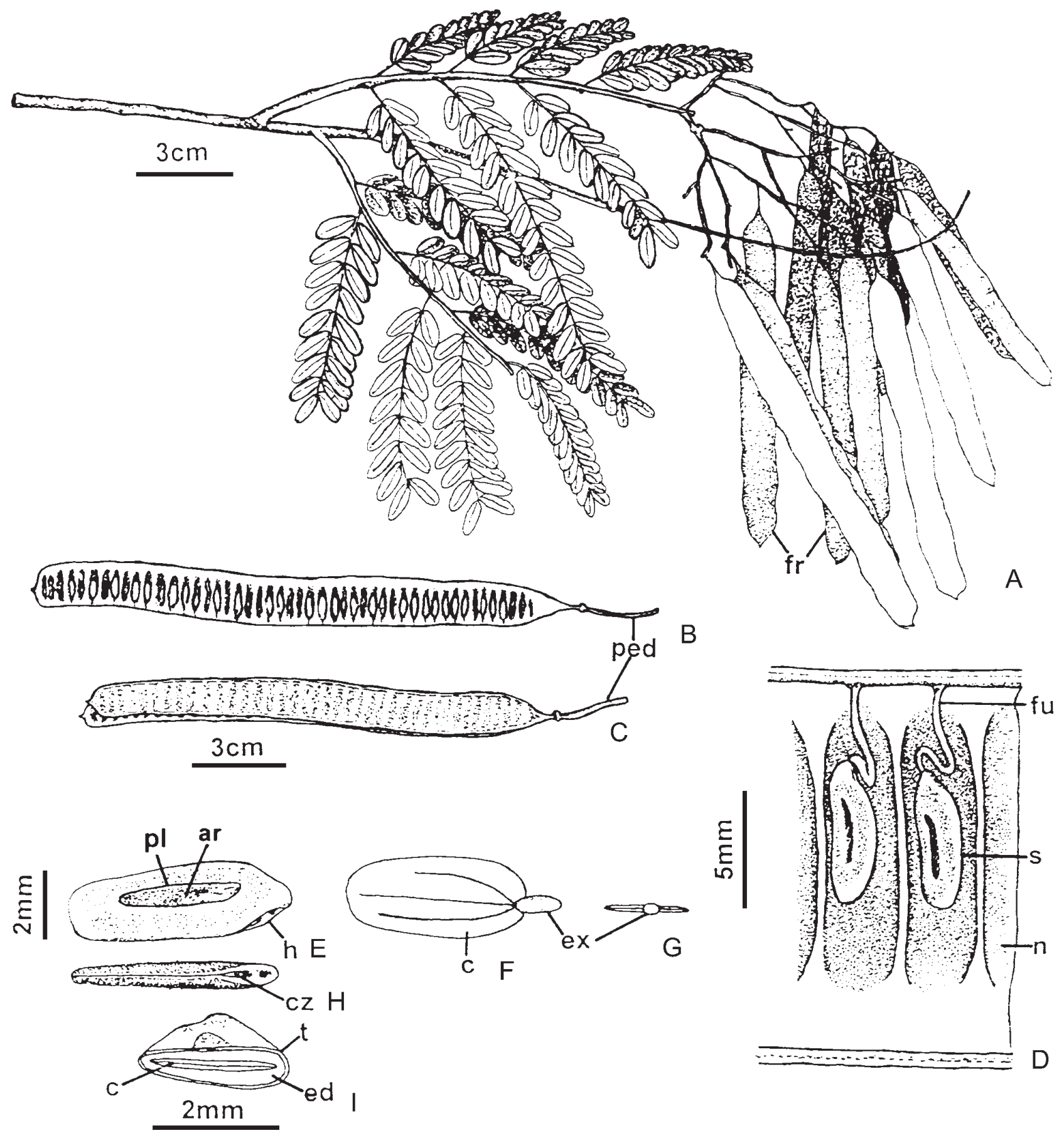

Figura 1. Aspectos morfológicos de frutos e sementes de Senna multijuga. A. Ramo com fruto. B. Disposição das sementes no fruto. C. Fruto fechado. D. Detalhe da semente no fruto, mostrando o funículo. E. Semente. F. Embrião. G. Corte no eixoembrionário. H. Semente, vista ventral. I. Corte transversal da semente. (ar = aréola; c = cotilédone; $\mathrm{cz}=$ calaza; ex = eixo-embrionário; ed $=$ endosperma; $\mathrm{fr}=$ fruto $; \mathrm{fu}=$ funículo $; \mathrm{h}=$ hilo $; \mathrm{n}=$ núcleo seminífero; ped = pedúnculo; $\mathrm{pl}=$ pleurograma; $\mathrm{s}=$ semente; $\mathrm{t}=$ tegumento).

Figure 1. Morphological aspects of fruits and seeds of Senna multijuga. A. Branch with fruit. B. Seeds in the fruit. C. Closed fruit. D. Detail of seed into the fruit showing the funiculus. E. Seed. F. Embryo. G. Section in embryo axis. H. Seed, ventral view. I. Transversal section in seed. $(\mathrm{ar}=$ areole; $\mathrm{c}=$ cotyledon; $\mathrm{cz}=$ chalaza; ex = embryo axis; ed = endosperm; $\mathrm{fr}=$ fruit; $\mathrm{fu}=$ funiculus; $\mathrm{h}=$ hilum; $\mathrm{n}=$ seed nucleus; ped = peduncle; $\mathrm{pl}=$ pleurogram; $\mathrm{s}=$ seed $\mathrm{t}=$ seed coat). 
Morfologia da semente (figura 1D-H) - As sementes são oblongas, comprimidas lateralmente, encerradas nas valvas formando leves depressões, com comprimento médio de $6,4 \mathrm{~mm}$ (variando de 5,8 a 7,0 mm, com desvio padrão de $0,4 \mathrm{~mm}$ e coeficiente de variação de 6,3\%), largura média de 2,4 $\mathrm{mm}$ (variando de 1,9 a $2,9 \mathrm{~mm}$, com desvio padrão de $0,1 \mathrm{~mm}$ e coeficiente de variação de $12,5 \%$ ) e espessura média de $0,8 \mathrm{~mm}$ (variando de 0,7 a $0,9 \mathrm{~mm}$, com desvio padrão de $0,1 \mathrm{~mm}$ e coeficiente de variação de 12,5\%). Ápice arredondado, levemente obtuso ou truncado, base afinada, reentrante na região hilar. A superfície é de coloração verde-musgo a marromesverdeada, glabra, brilhante e lisa; no centro da semente, em ambos os lados, observa-se uma aréola de coloração marrom-escura, alongada a estreita circundada pelo pleurograma fechado. Hilo sub-basal, caracterizado por uma pequena depressão arredondada e homócroma; micrópila e rafe inconspícuas; calaza linear, ventral, de coloração marrom-escura, com porção basal suavemente intumescida e alongada, seguida de uma estreita faixa linear de coloração enegrecida. Tegumento muito delgado, de coloração vermelho-telha, seco, membranáceo, recoberto por uma fina camada cerosa; endosperma abundante, periférico e carnoso. O embrião é cotiledonar, axial (figura $1 F)$, invaginado, carnoso e ocupando mais de um quarto da semente. Cotilédones foliáceos, tenros, plano-côncavos, retos, paralelos, oblongos, bastante delgados, com superfície lisa e brilhante, com nervação trinérvea visível; base levemente sagitada, mais larga do que o ápice obtuso e bordos inteiros. O eixo hipocótilo-radícula é reto (figura 1F), curto, cilíndrico, longitudinalmente oblongo, com ápice obtuso; transversalmente é achatado tendendo a elíptico.

A presença de endosperma em Caesalpinioideae também foi observada nos gêneros Peltophorum, Tachigalia e Schizolobium (Oliveira \& Pereira 1984) e, nas espécies Cassia fistula L. (Araújo \& Matos 1991) e Dimorphandra mollis Benth. (Ferreira et al. 2001). Segundo Gunn (1981), que estudou 5 tribos, com 110 gêneros e 1.900 espécies desta subfamília, o endosperma estava presente em $32 \%$ dos gêneros. Em geral, as sementes apresentam endosperma duro e vítreo em estado seco e, quando hidratado, o endosperma tem aspecto gelatinoso, aumentando o seu volume e causando a ruptura da testa. De acordo com o autor, filogeneticamente as sementes primitivas contém mais endosperma do que as sementes mais evoluídas. Tal caráter, quando presente, pode ser observado na forma de uma densa ou fina camada circundando o embrião.

A presença de pleurograma, como observado nesta espécie, também é comum nas Caesalpinioideae, sendo um caráter bastante válido para identificação (Gunn 1981). Este caráter também foi observado em Cassia organensis Glaz. ex Harms por Barroso et al. (1999) formando um pleurograma fechado. Segundo os autores, tal caráter apresenta forma variável, mas fornece subsídios para identificação em nível específico. O pleurograma também foi observado em sementes de Cassia fistula L., como sendo levemente visível (Araújo \& Matos 1991).

Os pleurogramas, do ponto de vista da ontogenia, podem apresentar diferenças entre gêneros, tribos e subfamílias (Gunn 1981). Segundo o autor, em sementes de Mimosoideae é decorrente de uma quebra na camada paliçádica exotestal, enquanto em Caesalpinioideae como Senna spp. e outros gêneros isto é resultante de uma diferença nas próprias camadas de células paliçádicas.

Morfologia das plântulas - $1^{\underline{a}}$ fase (figura $2 A-G$ ) - A germinação é epígea fanerocotiledonar. A radícula é cilíndrica, tenra, aveludada e levemente mais dilatada do que o hipocótilo, rompendo o tegumento na região basal da semente; os pêlos radiculares são simples, finos, hialinos, tenros, brilhantes, longos e tortuosos. Uma leve dilatação da extremidade apical da radícula marca o início da coifa, que é glabra, de coloração pérola-escuro, cilíndrica, alongada e termina numa ponta aguda. $\mathrm{O}$ coleto é curto, cilíndrico e esbranquiçado, delimitado pela abundante pilosidade que marca o início da radícula; em algumas plântulas caracteriza-se por um leve alargamento do hipocótilo. O hipocótilo é cilíndrico, herbáceo, de coloração verde-clara, com pêlos finos, curtos e esparsos. No início do desenvolvimento com aspecto geniculado e que rapidamente passa a ereto, erguendo acima do solo os cotilédones ainda envolvidos pelo tegumento. Os cotilédones são verde-escuros, coriáceos, opostos, peciolados, oblongos, com ápice obtuso ou arredondado, base ligeiramente truncada e bordos inteiros, apresentam face abaxial em forma de quilha e adaxial plano-côncava, onde a nervação trinérvea é evidente. O pecíolo é curto, cilíndrico e de coloração verde-claro.

Germinação fanerocotiledonar à semelhança aqui observada foi descrita também para as espécies Hymenaea courbaril L. (Flores \& Benavides 1990); Cassia fistula L. (Araújo \& Matos 1991); Caesalpinia peltophoroides Benth., Cassia leptophylla Vog., Hymenaea courbaril L. e Peltophorum dubium (Spreng.) Taub. (Soriano \& Torres 1992), Hymenaea stigonocarpa Mart. ex Hayne (Botelho et al. 2000) e Dimorphandra mollis Benth. (Ferreira et al. 2001).

Morfologia das plântulas - 2 ${ }^{a}$ fase (figura $2 \mathrm{H}-\mathrm{M}$ ) - As plântulas apresentam sistema radicular pivotante, com 

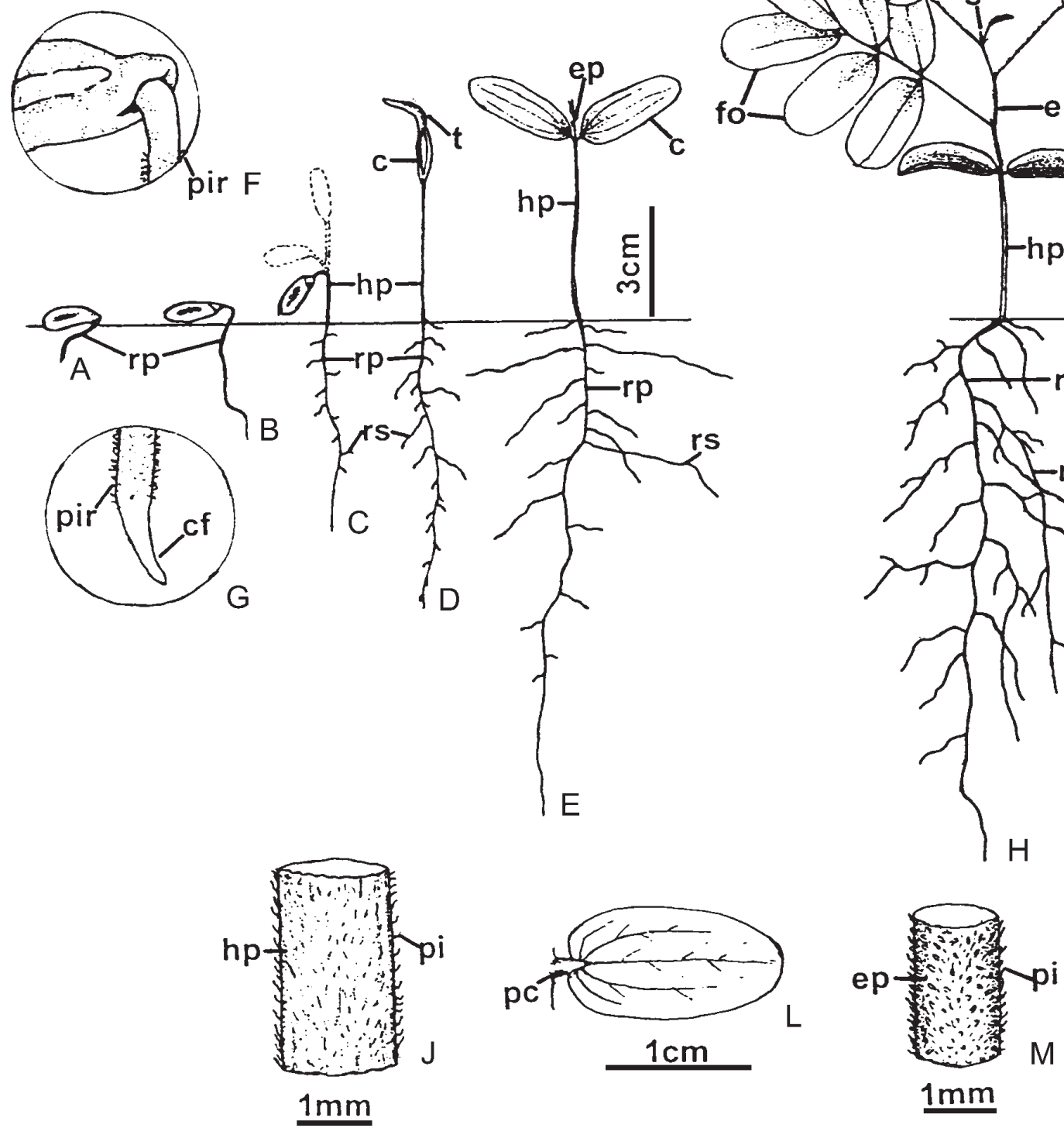

Figura 2. Aspectos morfológicos de plântulas de Senna multijuga. A-G. Aspectos da germinação, desde a emissão da raiz primária até emissão dos protófilos. H. Plântula com protófilos formados. I. Gema apical. J. Aspectos do hipocótilo. L. Cotilédone. $\mathrm{M}$. Aspectos do epicótilo. $(\mathrm{c}=$ cotilédone; $\mathrm{cf}=\mathrm{coifa}$; ep = epicótilo; et = estípula; fo = folíolo; $\mathrm{g}=\mathrm{gema}$ apical; $\mathrm{hp}=$ hipocótilo; $\mathrm{pe}=$ pecíolo; $\mathrm{pi}=$ pêlo; $\mathrm{pir}=$ pêlos radiculares; $\mathrm{rp}=$ raiz primária; $\mathrm{rs}=$ raiz secundária; $\mathrm{t}=$ tegumento).

Figure 2. Morphological aspects of seedlings of Senna multijuga. A-G. Aspects of germination, since radicle protrusion until eophyll formation. H. Seedlings with formed eophyll. I. Apical bud. J. Hypocotil. L. Cotyledon. M. Epicotyl aspects. (c = cotyledon; cf = root cap; ep = epicotyl; et = exstipule; fo = leaflet; $\mathrm{g}=$ apical bud; $\mathrm{hp}=$ hypocotil; $\mathrm{pe}=$ petiole; $\mathrm{pi}=$ hair; pir = root hairs; $r p=$ primary root; $r s=$ secondary root; $t=$ seed coat $)$. 
raiz axial bastante desenvolvida. O hipocótilo é cilíndrico, brilhante, estriado, verde-amarelado na base e verdeclaro no ápice; pubescente, com pêlos simples, finos, curtos, macios, brilhantes, hialinos e curvos. O epicótilo é cilíndrico, verde-claro, brilhante, com dois tipos de pêlos: o primeiro é curto, muito fino, hialino, tortuoso e geralmente curvado; o outro presente em maior intensidade é curto com ápice agudo, base mais alargada e de coloração vermelho-telha. O caule jovem é sub-herbáceo, verdeclaro, brilhante e com a mesma pilosidade do epicótilo. No entanto, apresenta pêlos mais crassos de coloração amarelo-escura nos entrenós mais jovens, que são relativamente curtos. Os cotilédones são persistentes, com limbo levemente pendente, verde-escuro em ambas as faces, puncticulado e com nervação visível. Pecíolo curto, verde-claro, crasso, cilíndrico e glabro. O nó cotiledonar caracteriza-se por estreita e brusca dilatação, anular e de contorno arredondado. Os protófilos são compostos, alternos, peciolados, pulvinados, apresentando aumento constante no número de pares de folíolos à medida que novas folhas vão surgindo; os folíolos são opostos, peciolulados, oblongos, de ápice geralmente arredondado, base arredondada ou obtusa e bordos inteiros. $\mathrm{Na}$ base de inserção de cada metáfilo existem duas estípulas verde-claras, pubescentes, sésseis, espatuladas e com ápice acuminado. As plântulas apresentam um rápido desenvolvimento do epicótilo e um acelerado processo de formação e expansão de novas folhas.

A presença de estípulas também foi descrita por Finger et al. (1979) para as espécies Apuleia leiocarpa (Vog.) Macbr. e Senna macranthera (Collad.) H.S. Irwin \& Barneby e para Caesalpinia peltophoroides e Hymenaea courbaril (Soriano \& Torres 1992).

Morfologia da muda (figura 3A-I) - Dois meses e meio após a germinação, as mudas apresentaram uma altura média de $34,5 \mathrm{~cm}$ e um diâmetro médio do colo de 4,2 $\mathrm{mm}$. O sistema radicular é pivotante, com abundante ramificação lateral; a raiz axial é sinuosa, cilíndrica e fibrosa, medindo de 4,5 a 5,0 mm de diâmetro no colo, afinando gradualmente em direção a porção terminal; a superfície é glabra, amarelada e altamente lenticelada (lenticelas arredondadas, ovais ou oblongas, claras e de aparência verruciforme); apresenta descamações longas ou curtas, foliáceas e enegrecidas, além de curtas raízes e finas rachaduras marrom-escuras, o que lhe confere aspecto reticulado. As raízes laterais são enegrecidas, cilíndricas, glabras, bastante ramificadas e densas, homogeneamente distribuídas em toda a extensão da raiz principal. O colo é cilíndrico, caracterizado geralmente por abrupto intumescimento da base do hipocótilo e pela gradual variação de coloração do hipocótilo e da raiz pivotante; com superfície lenticelada e com descamações. O hipocótilo é cilíndrico e fibroso, com superfície glabra, rugosa, de coloração verde-escura, opaca, com rachaduras finas e curtas, descamações longitudinais finas, curtas ou longas, de coloração marrom-escura e com grande quantidade de lenticelas esbranquiçadas, arredondadas, ovais ou oblongas, em sentido transversal. O epicótilo é bastante curto, com grande quantidade de lenticelas arredondadas e esbranquiçadas e com intensa formação de rachaduras. O caule jovem apresenta entrenós basais mais curtos do que os apicais e a superfície com as mesmas características do epicótilo; os entrenós apicais são de consistência sub-herbácea, com superfície de coloração verde-clara, brilhante, áspera, com o mesmo tipo de pêlos observados na fase de plântula e, também, com grande quantidade de lenticelas arredondadas e esbranquiçadas. Os cotilédones são caducos, deixando uma pequena cicatriz esbranquiçada, transversalmente em forma de boca, sobre a qual há uma gema axilar globosa, verdeclara, brilhosa, que se destaca sobre o caulículo verdeescuro e opaco. Os metáfilos são idênticos aos protófilos descritos na fase de plântula; no entanto, é comum os dois primeiros estarem ausentes ou em processo de senescência, seguido da queda. Os folíolos são peciolados, discolores (verde escuro na face adaxial e claro na abaxial), apresentam limbo oblongo, obovado-oblongo ou oblongo-cuneado; base arredondada, aguda, obtusa, acuneada ou assimétrica; ápice obtuso ou arredondado, apresentando minúsculo e tenro apículo estipuliforme; bordos inteiros, retos, com pêlos finos, longos e lustrosos, deitados em direção ao ápice dos folíolos com faces planas, lisas, com face adaxial glabra e abaxial pilosa (com pêlos finos, longos, hialinos, brilhantes, filiformes e curvos); nervação peninérvea e com nervura principal excurrente. O pecíolo é verde-claro, seríceo como o epicótilo, com face adaxial acanalada e abaxial arredondada na base e carenada na porção terminal. Peciólulo muito curto constituindo-se num pulvínulo relativamente crasso, globoso, cilíndrico, brilhante e glabrescente. Raquis de coloração verde-clara, acanalada na face adaxial e arredondada na abaxial, aveludada, flexível e macia. $\mathrm{Na}$ inserção de cada par de folíolos, na face adaxial da raquis, projeta-se uma glândula estipuliforme, crassa, alongada, de coloração amarelada e formato cônico. A extremidade apical apresenta-se envolvida por grande quantidade de estípulas. Gemas axilares, triangulares, verde-claras e aveludadas, apresentam-se protegidas por duas estípulas em forma de espada, persistentes, pilosas na face externa e lisas e glabras na face interna. 


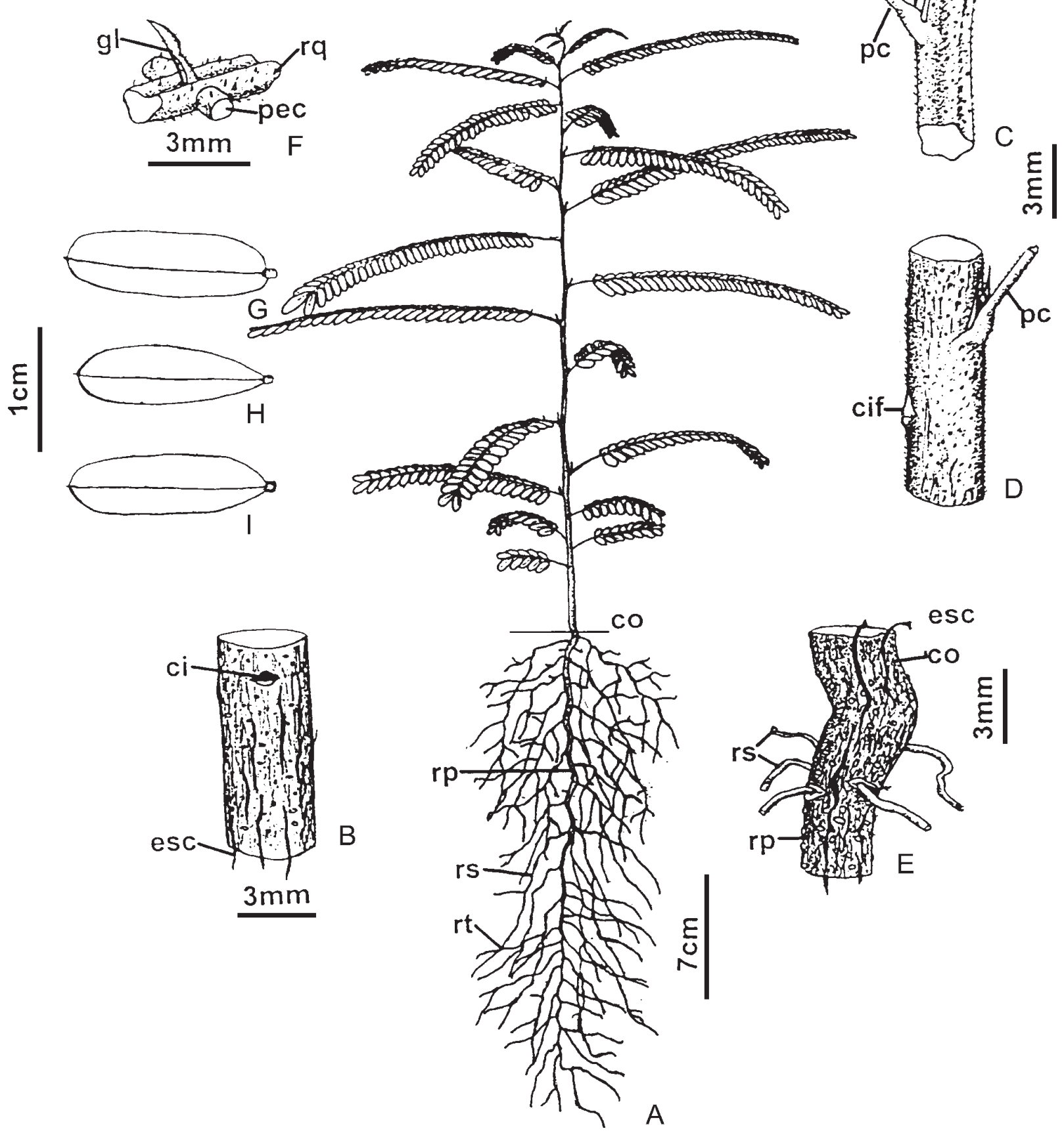

Figura 3. Aspectos morfológicos da muda de Senna multijuga. A. Aspecto da muda bem formada. B. Detalhes da superfície do hipocótilo. C-D. Aspecto transversal do ápice e da base do caule jovem, respectivamente. E. Aspectos do colo e da base radicial. F. Detalhe da glândula observada entre cada par de folíolos. G-I. Formas dos folíolos. (ci = cicatriz cotiledonar; cif = cicatriz foliar; $\mathrm{co}=$ coleto; esc $=$ escamas; et $=$ estípula; $\mathrm{gl}=$ glândula; pe = pecíolo; pec = peciólulo; $\mathrm{rp}=$ raiz primária; $\mathrm{rq}=$ raquis; $\mathrm{rs}=$ raiz secundária; $\mathrm{rt}=$ raiz terciária) .

Figure 3. Morphological aspects of seedling of Senna multijuga. A. Mature seedlings. B. Detail of hypocotil surface. C-D. Transversal aspects of apical and base young stem, respectively. E. Aspects of base young stem and root base. F. Detail of gland between leaflets. G-I. Leaflet forms. (ci = cotyledon cicatrix; $\mathrm{cf}=$ leaf cicatrix; $\mathrm{co}=$ collet; esc $=$ scale; et $=$ stipules; $\mathrm{gl}=$ gland; $\mathrm{pe}=$ petiole; $\mathrm{pec}=$ petiolule; $\mathrm{rp}=$ primary root; $\mathrm{rq}=$ rachis; $\mathrm{rs}=$ secondary root; $\mathrm{rt}=$ tertiary root $)$. 


\section{Referências bibliográficas}

ABREU, D.C.A., KUNIYOSHI, Y.S., MEDEIROS, A.C.S. \& NOGUEIRA, A.C. 2005. Caracterização morfológica de frutos e sementes de cataia (Drimys brasiliensis Miers - Winteraceae). Revista Brasileira de Sementes 27:67-74.

AMARO, M.S., MEDEIROS FILHO, S., GUIMARÃES, R.M. \& TEÓFILO, E.M. 2006. Morfologia de frutos, sementes e de plântulas de janaguba (Himatanthus drasticus (Mart.) Plumel. - Apocynaceae). Revista Brasileira de Sementes 28:63-71.

AMORIM, I.L., FERREIRA, R.A., DAVIDE, A.C. \& CHAVES, M.M. 2006. Aspectos morfológicos de trema. Revista Brasileira de Sementes 28:86-91.

ARAUJO, E.C., MENDONÇA, A.V.R., BARROSO, D.G., LAMÔNICA, K.R. \& SILVA, R.F. 2004. Caracterização morfológica de frutos, sementes e plântulas de Sesbania virgata (Cav.) Pers. Revista Brasileira de Sementes 26: 105-110.

ARAÚJO, S.S. \& MATOS, V.P. 1991. Morfologia da semente e de plântula de Cassia fistula L. Revista Árvore 15:217-223.

ARAÚJO-NETO, J.C., AGUIAR, I.B., FERREIRA, V.M. \& PAULA, R.C. 2002. Caracterização morfológica de frutos e sementes e desenvolvimento pós-seminal de monjoleiro (Acacia polyphylla DC.). Revista Brasileira de Sementes 24:203-211.

BARROSO, G.M., MORIM, M.P., PEIXOTO, A.L. \& ICHASO, C.L.F. 1999. Frutos e sementes: morfologia aplicada à sistemática de dicotiledôneas. Editora UFV, Viçosa.

BELTRATI, C.M. 1992. Morfologia e anatomia de sementes. Editora UNESP, Rio Claro.

BOTELHO, S.A., FERREIRA, R.A., MALAVASI, M.M. \& DAVIDE, A.C. 2000. Aspectos morfológicos de frutos, sementes, plântulas e mudas de jatobá-docerrado (Hymenaea stigonocarpa Mart. ex Hayne) Leguminosae Caesalpinioideae. Revista Brasileira de Sementes 22:144-152.

CARVALHO, P.E.R. 1994. Espécies florestais brasileiras: recomendações silviculturais potencialidades e uso da madeira. Embrapa-CNPF/SPI, Brasília.

CHAVES, M.M.F. 1994. Descrição morfológica de sementes, de plântulas e de mudas de 10 espécies arbóreas pioneiras na microrregião de Viçosa, Minas Gerais. Dissertação de mestrado, Universidade Federal de Viçosa, Viçosa.

CUNHA, M.C.L. \& FERREIRA, R.A. 2003. Aspectos morfológicos da semente e do desenvolvimento da planta jovem de Amburana cearensis (Arr. Cam.) A.C. Smith - cumaru - Leguminosae Caesalpinioideae. Revista Brasileira de Sementes 25:89-96.

DAVIDE, A.C., FARIA, J.M.R. \& BOTELHO, S.A. 1995. Propagação de espécies florestais. FAEPE, UFLA, Lavras.
DUKE, J.A. \& POLHILL, R.M. 1981. Seedlings of Leguminosae. In Advances in legume systematics (R.M. Polhill \& P.H. Raven, eds.). Royal Botanic Gardens, Kew. p.941-949.

FELICIANO, A.L.P. 1989. Estudo da germinação de sementes e desenvolvimento da muda, acompanhado de descrições morfológicas de dez espécies arbóreas ocorrentes no semi-árido nordestino. Dissertação de mestrado, Universidade Federal de Viçosa, Viçosa.

FERREIRA, A.A., GOMIDE, C.J., SILVA, E.A.M., SILVA, H. \& MARIA, J. 1995. Anatomia das espermatófitas. Universidade Federal de Viçosa, Viçosa.

FERREIRA, R.A., BOTELHO, S.A., DAVIDE, A.C. \& MALAVASI, M.M. 2001. Morfologia de frutos, sementes, plântulas e mudas de Dimorphandra mollis Benth. - faveira (Leguminosae Caesalpinioideae). Revista Brasileira de Botânica 24:303-309.

FERRI, M.G., MENEZES, N.L. \& MONTEIRO, W.R. 1981. Glossário ilustrado de botânica. Nobel, São Paulo.

FINGER, Z., RAMALHO, R.S., BRANDI, R.M. \& CÂNDIDO, J.F. 1979. Estudos dendrológicos da regeneração natural na microrregião de Viçosa, MG. I. Identificação e descrição de algumas espécies. Revista Árvore 3:94-119.

FLORES, E.M. \& BENAVIDES, C.E. 1990. Germinación y morfología de la plántula de Hymenaea courbaril L. (Caesalpinaceae). Revista de Biologia Tropical 38:91-98.

GUNN, C.R. 1981. Seed topography in the Fabaceae. Seed Science \& Tecnology 9:737-757.

IRWIN, H.S. \& BARNEBY, R.C. 1982. The American Cassiinae: a synoptical revision of Leguminosae Tribe Cassieae Subtribe Cassiinae in the New World. Memoirs of the New York Botanical Garden. v.35.

KUNIYOSHI, Y.S. 1983. Morfologia da semente e da germinação de 25 espécies arbóreas de uma floresta com araucária. Dissertação de mestrado, Universidade Federal do Paraná, Curitiba.

LAWRENCE, G.H.M. 1973. Taxonomia das plantas vasculares. Fundação Calouste Gulbekian, Lisboa.

LIMA, M.P.M. 1985. Morfologia dos frutos e sementes dos gêneros da tribo Mimoseae (Leguminosae-Mimosoideae) aplicada à Sistemática. Rodriguesia 37:53-78.

LIMA, H.C. 1989/1990. Tribo Dalbergiae (Leguminosae Papilionoideae): morfologia dos frutos, sementes, plântulas e sua aplicação na sistemática. Arquivos do Jardim Botânico do Rio de Janeiro 30:1-42.

LORENZI, H. 1992. Árvores brasileiras: manual de identificação e cultivo de plantas arbóreas nativas do Brasil. Editora Plantarum, Nova Odessa.

MELO, M.F.F. \& VARELA, V.P. 2006. Aspectos morfológicos de frutos, sementes, germinação e plântulas de espécies florestais da Amazônia. I. Dinizia excelsa Ducke (angelim-pedra). II Cedrelinga catenaeformis Ducke (cedrorana) - Leguminosae Mimosoideae. Revista Brasileira de Sementes 28:54-62. 
OLIVEIRA, E.C. 1993. Morfologia de plântulas florestais. In Sementes florestais tropicais (I.B. Aguiar., F.C.M, Piña-Rodrigues \& M.B. Figliolia, eds.). Abrates, Brasília, p.175-214.

OLIVEIRA, E.C. \& PEREIRA, T.S. 1984. Morfologia dos frutos alados em Leguminosae - Caesalpinioideae Martiodendron Gleason, Peltophorum (Vogel) Walpers, Sclerolobium Vogel, Tachigalia Aublet e Schizolobium Vogel. Rodriguesia 36:35-42.

OLIVEIRA, D.M.T. 1999. Morfologia de plântulas e plantas jovens de 30 espécies arbóreas de Leguminosae. Acta Botanica Brasilica 13:263-269.

PINHEIRO, A.L. 1986. Estudos de características dendrológicas, anatômicas e taxonômicas de Meliaceae na microrregião de Viçosa. Dissertação de mestrado, Universidade Federal de Viçosa, Viçosa.

RADFORD, A.E., DICKISON, W.C., MASSEY, J.R. \& BELL, C.R. 1974. Vascular plants systematic. Harper and Row, New York.

RODERJAN, C.V. 1983. Morfologia do estádio juvenil de 24 espécies arbóreas de uma floresta com araucária. Dissertação de mestrado, Universidade Federal do Paraná, Curitiba.

RODRIGUES, F.C.M.P. \& ARAKI, S.M.N. 1988. Formação da semente. In Manual de análise de sementes florestais (F.C.M. Piña Rodrigues, ed.). Fundação Cargill, Campinas. p.10-24.
SALLES, H.G. 1987. Expressão morfológica de sementes e plântulas I. Cephalocereus fluminensis (Miq.) Britton e Rose (Cactaceae). Revista Brasileira de Sementes 9: 73-81.

SILVA, L.L. \& PAOLI, A.A.S. 2006. Morfologia e anatomia da semente de Balfourodendron riedelianum (Engler) Engler - Rutaceae. Revista Brasileira de Sementes 28: 16-20.

SILVA, L.M.M. \& MATOS, V.P. 1998. Morfologia de frutos, sementes e plântulas de catingueira (Caesalpinia pyramidalis Tul. - Caesalpinaceae) e de juazeiro (Zizyphus joazeiro Mart. - Rhamnaceae). Revista Brasileira de Sementes 20:263-269.

SORIANO, S. \& TORRES, R.B. 1992. Descrição de plântulas de árvores nativas. In Anais do IX Congresso da Sociedade Botânica de São Paulo. Sociedade Botânica de São Paulo, Campinas, p.27-46.

SOUTO, L.S. \& OLIVEIRA, D.M.T. 2005. Morfoanatomia e ontogênese do fruto e semente de Byrsonima intermedia A. Juss. (Malpighiaceae). Revista Brasileira de Botânica 28:697-712.

SOUZA, A., MOURÃO, K.S.M. \& SOUZA, L.A. 2005. Morfologia e anatomia do fruto e da semente em desenvolvimento de Pilocarpus pennatifolius Lem. (Rutaceae). Revista Brasileira de Botânica 28:745-754.

VIDAL, W.N. \& VIDAL, M.R.R. 1984. Botânica: organografia. $3^{\underline{a}}$ ed. Universidade Federal de Viçosa, Viçosa. 